\title{
Trusting the poor: Cash grants and the caring bureaucrat in Kenya
}

\section{Abstract}

Across the world, attempts are being made to challenge and rework bureaucratic hierarchies. One such attempt is the policy to give cash with no-strings attached to the poor. Lying at the heart of these grants is the belief that it is these people, and not experts, who know what they need to do to improve their lives. Benefactors seek to trust the poor by removing the regulation and bureaucracy from the charitable gift. But in one slum in Nairobi these efforts were met with opposition by local, slum-level bureaucrats, who took a keen interest in shaping and managing the visibility of behaviour of the poor they represented. I argue that was a form of care that took place in the context of particular social relationships, norms and values within which the grants were embedded. This care work highlighted not the legitimacy of hierarchies but the work that is involved in making them work. Against popular and scholarly images of the bureaucrat, this article calls for a recognition of the ethical and caring dimension of the bureaucrat, an actor cast, perhaps too often, as a morally suspect intermediary. It also calls for more scrutiny of the ostensibly laudable goals of on the one hand, extending trust, and on the other hand, flattening, inverting and hollowing out hierarchies that are taking place across the globe.

Keywords:

Trust; Charity; Bureaucracy; Cash Transfers; Grants; Hierarchy; Kenya

\section{Introduction}

What happens if you just give money to the poor? The question, while hardly a new one, has becoming particularly pertinent in recent years. Since the turn of the century, institutions 
throughout the world have increasingly experimented with giving cash grants, often called cash transfers, to poor and vulnerable households. Those researchers who have sought to answer the question have found time and time again that the poor recipients use the money responsibly, leading to positive educational, health and income outcomes (for a summary see Hanlon, Barrientos, and Hulme 2010). As a result, these grants are seen as one of the most exciting policy ideas around today for the alleviation of poverty and suffering.

While these studies have generated crucial insights, I take a different tack in this article that places the grants in a wider social context (Olivier de Sardan and Piccoli 2018). In doing so I contribute to discussions concerning charity, bureaucracy, hierarchy and the notion of trust. The article draws on sixteen months of fieldwork between 2010 and 2012 in Nairobi, Kenya, including in one slum, Korogocho. There, over a quarter of the households were receiving unconditional grants. Unconditional because recipients, once selected, had no formal requirements placed on them to continue receiving the grant. While I documented the many ways in which the "free gift" of money was put to use, I focus in this article on what was not put to use. Namely, the loosely assembled, slum-level, bureaucratic army of NGO workers, social workers, community workers and community health workers who live and work in Korogocho. They have typically helped governmental and non-governmental institutions identify, train and track charitable recipients as well as distribute charitable aid. These actors operate not in a formal bureaucracy but rather in a more informal, fragmented one that is an integral part of those precarious charitable economies that have emerged in the towns and villages across Kenya as a result of several decades of development and humanitarian intervention. 
In the new paradigm of charitable assistance where cash is transferred directly to the recipient, moves are made to flatten, reverse and, by eschewing the intermediary, hollow out existing bureaucratic hierarchies. In this way, the unconditional grant is joined to a litany of related ideas from the closely related ideas of Universal Basic Income to seemingly unrelated ones such as the new experiments in peer-to-peer exchange drawing on blockchain technologies. These ideas all seek to remake society in their own image. Yet, in doing so they cast the bureaucrats and intermediaries as unnecessary, even morally suspect. Bureaucrats are branded, it is argued from those occupying a variety of political positions, from anarchism to libertarianism, as a vestige of an antiquated system, being considered at worse, as self-serving or, at best, as mere cogs in a violent, bureaucratic machine.

Quite predictably, the local bureaucrats in Korogocho disagreed with their apparent obsolescence. They asserted their vital role and demonstrated this by taking a keen interest in the behavior of the poor they represented. This involved them making visible what they thought was the poor's acceptable behavior, while hiding what they thought unacceptable. To make visible the right behavior required the reintroduction of new forms of regulations. This reintroduction of regulation can be interpreted, I argue, not as a technical error, nor as an attempt to show their worth, and nor as way in which bureaucrats assert a distinction between themselves and those they serve. While not attributing intentionality to these bureaucrats, I consider their acts as a fundamentally ethical form of care that sought to ensure the continued flow of resources between the government and donors to the community they represented. This care, I also argue, is a care which has a relationship as its object. When bureaucrats mistrusted the individual charitable recipients, or even when they trusted them but hid their behaviors, they were doing so to care for, and hopefully make trustworthy, the precarious structural relationship between the benefactors and the poor. This is a relationship that characterizes the 
global charitable economy that reaches into places like Korogocho; an economy which has become increasingly complex (Brown and Green 2017, 48). While mistrust is conventionally seen as an uncaring, even violent, act, it can, I show, be interpreted as a decidedly caring one when its object is a relationship. This interpretation expands our understanding of how bureaucrats are part of hierarchical relationships that structure redistribution in Kenya and beyond (Haynes 2012; Welker 2012; Ferguson 2013; Ansell 2014; Scherz 2014; Haynes and Hickel 2016). While not always successful, the acts constituted a form of mutuality which make sense within the wider relational infrastructure of the charitable economy, where the gaze of the donor remains fixed on the poor, even if the cash grants and their emphasis on trust give the allusion of breaking it.

Considering bureaucrats as a part of a mutuality runs up against both popular and scholarly representations of them. Indeed, critics of bureaucracy often rest on a long-standing assumption that it is simply amoral. However, as Paul du Gay (2000) has argued, this assumption ignores the ways in which bureaucrats partake in deeply ethical projects in which they strive towards being a 'good' bureaucrat, for instance by cultivating dispositions such as impersonality or a respect of hierarchy. In this article, I explore how the ethics of a particular type of bureaucracy might become especially apparent in the face of equally ethical infused attempts to disrupt bureaucratic hierarchies. I show how these emerged from long-standing relationships of charity, care, redistribution and claim-making within the precarious charitable economy in Korogocho and beyond, in which they are embedded.

Finally, I propose also that the bureaucrats' responses draw attention to questions that reaches beyond the specificities of cash grants in East Africa. What are we to make of apparently laudable aims such as trusting the poor or of flattening, inverting or hollowing out bureaucracy 
and hierarchies or even of attempts to move towards a post-bureaucratic world altogether? And what are we to make of the seemingly reactionary responses that insist on mistrust and of the importance of bureaucratic practices? The specific example presented in this article I suggest provides some answers to these questions, offering ideas that can nourish our investigation of other attempts to challenge and disrupt bureaucracy and hierarchy across the globe.

\section{Unconditional grants}

During my fieldwork, two unconditional grants were offered to selected residents of Korogocho, both of which targeted primarily female care-givers. In each, recipients received KSh2,000 (around USD22) per month. This was a significant sum, and for some of the poorest recipients even doubled their monthly income. The first grant to arrive in the slum, in 2004, was through a partnership - between the government and UNICEF - aimed at those caring for what became the category of orphans and vulnerable children (OVC). This child grant later became the Government of Kenya's flagship social protection initiative, with significant support from the World Bank. Today, around six million people, or approximately twelve percent of the population, are in a household receiving this grant. In Korogocho, every two months the child grant recipients would receive notification that their grant was available and would make the short journey to the state Post Office to collect it. While during my fieldwork these grants reached relatively few people, recipients continued to receive it until their youngest child had reached the age of eighteen, and so were often on the program for a long period of time.

The second grant to arrive in Korogocho was brought by a transnational humanitarian NGO, first in 2009 and then again in 2011, during my fieldwork. It was part of a global push by humanitarian organizations, including the WFP, to replace traditional food aid with alternative non-food technologies including vouchers and cash. This humanitarian grant reached a far 
greater number of the households - those deemed particularly vulnerable to hunger - but the length of time one would receive the grant was limited to eight months. Unlike the government grant which arrived through the Post Office every two months, the humanitarian grant arrived in recipients' mobile money account roughly each month. A local NGO, Living Faith, which had worked with the people of Korogocho for decades, was contracted to provide some of the, now more limited, bureaucratic administration of the program. This administration involved their own social workers collaborating with the community workers and community health workers in the slum to survey the population so as to identify the most vulnerable households. ${ }^{1}$

Both grants were part of the larger charitable economy that involves the voluntary transfer of money from bilateral and multilateral donors, as well as private individuals, through governments, NGOs or partnerships between the two, to those designated as in need of assistance. This economy can be understood as being motived by an understanding of a formal identity between a giver and a receiver (Stirrat and Henkel 1997; Wilson and Brown 2008). Donors consider the recipients of their charitable gifts as being deprived of the same fundamental and universal rights they themselves possess (Wilson and Brown 2008, 12). As the money enters into the charitable economy, it is transformed through particular regulatory processes into specific gifts that seek to fulfil these rights and thus to produce a substantive rather than merely formal identity. Yet, donors also make decisions around what kinds of rights, or what are more frequently referred to as needs, are important for their recipients, while at the same time, holding ever shifting ideas about the characteristics of their recipients. Traditionally, charitable recipients have been considered as lacking the necessary knowledge and skill to improve their lives. As a result, they are subjected to various forms of pedagogy and monitoring. These targets are often either denied material support or offered it in forms, such as loans, which require repayment. The latter are part of a more general strategy to 
"empower" the poor and encourage them to become independent from the charitable gift itself, an aspect of neoliberal economic policy which has been extensively explored by anthropologists (Elyachar 2005; Moodie 2008; Welker 2012; Guérin 2014). ${ }^{2}$

Empowerment gifts have sought to recognize the industriousness of the poor but have been criticized for their singular pro-market focus on indebtedness as a poverty alleviation strategy and their emphasis on income generation in the informal economy. In certain ways, unconditional cash grants have challenged this approach, accompanied as they have been with a greater recognition of the diverse knowledge, skills and strategies of the poor. Putting this point forward, the Chair of the Cash Transfer Learning Partnership (CaLP) in Nairobi told me in an interview early in my fieldwork that, "Cash transfers are a big part of the solution...It's good to give cash, it's flexible, and it's treating poor people not as stupid." ${ }^{3}$ The poor, according to this NGO worker as well as others I met, are knowledgeable, have the wisdom to make good judgements, and can use this knowledge and wisdom gained throughout their lives, to make appropriate decisions. What is particularly interesting is the way that the NGO worker's views respond to the concerns that anthropologists have had for many years. Anthropologists have long been worried about "expert" knowledge and paternalism, having documented its many adverse effects (Goodell 1985). Most recently, writing about recent behavioral psychological theories of paternalism, for instance, Veena Das has worried that paternalism "ends up in a distrust of the poor and their ability to take responsibility for themselves" (Das 2015, 198). Das' concern echoes earlier work in anthropology that critiqued how the development apparatus portrayed the poor as "ignorant" (Hobart 1993); that is, as subjects whose particular (lack of) knowledge rendered them sufficiently untrustworthy to secure their own well-being, and which justified the use of paternalistic policies. 
Despite this move to trust the poor, the poor still had to be identified as such. Yet while almost everyone in Korogocho considered themselves impoverished, the grants had their eyes set on a particular, more vulnerable or poorer, subset. As expected, this involved intensive bureaucratic activity. ${ }^{4}$ Yet, what was most interesting was the aftermath of the activity. Once the flurry of this enrolment process had died down, I was struck by the paucity of formal and planned bureaucracy, expert knowledge and regulation. There were no workshops for grant recipients to attend, and barely any meetings. Moreover those receiving grants were not individually monitored. ${ }^{5}$ The sites that scholars following Foucault $(1991,1979)$ have found productive for investigating the formation of subjectivities and which are prevalent in the various institutional efforts to change people's lives were in extremely short supply. The grants, then, represent a divergence from traditional and contemporary charity, which has its origins in the application of regulation and expert knowledge (Sealander 2003). ${ }^{6}$

Regulation and expert knowledge is reduced not only because of its apparent bureaucratic inefficiencies but because, crucially, it is seen as doing violence to the poor's freedom to put their knowledge and skills, which have now been recognized as superior to the experts (here, an inversion of hierarchy), to use in their own life strategies. In this way, the grants were part of a larger anti-bureaucratic impulse, imbued with what Paul du Gay has argued to be a "thoroughly romantic belief that the principle of a full and free exercise of personal capacities is akin to a moral absolute for human conduct." (Du Gay 2000, 3). This accords with the reference made by the NGO worker to flexibility. In the grants, traditional charitable gifts have been transformed into the more flexible unmediated gift of money. Unmediated because the grants take the form of money which has the explicit property of a medium of exchange ${ }^{7}$, which, as Simmel argued, expands individual freedom. But the grant is also unmediated in the 
charitable economy because it seeks to avoid the traditional policy activities of guiding or checking individual recipients.

Finally, the grants also challenge some of the more simplified dichotomies between liberalism and social forms that are seen as illiberal. Grants, as a form of social protection or humanitarianism, combine ideas around dependency and material support with those concerning autonomy and self-realization. In this manner, they echo Foucault's suggestion that social security policies in France should offer "maximum independence" (Foucault 1990, 165). Foucault himself exampled Milton Friedman's negative income tax proposal as a policy that would offer assistance, in "a very liberal and much less bureaucratic and disciplinary way" (Foucault 2008, 207). Understandably then, for certain commentators and activists, as with the NGO worker above, these grants should be celebrated for treating the poor with a dignity that comes about from trusting them to make their own decisions without the heavy hand and the penetrating eye of the technocratic expert. Yet, as we will see, the grants emerged out of social relationships, norms and values of the existing charitable economy that had important implications.

\section{Charity, trust and the donor gaze}

Once recipients in Korogocho had been selected, all that remained was for them to collect their grant. Those receiving the humanitarian grant only had to switch on their phone and wait for the ping indicating the money had been delivered to their mobile money account. Yet for the bureaucrats, looming over this now curtailed bureaucracy was a lingering expectation that the grants in Korogocho may, at some point, be evaluated. In an interview, the Chief Operating Officer of GiveDirectly, a well-established charitable institution that experiments with unconditional grants in Kenya had this to say: "There's an assumption out there that we need to monitor how poor people spend their funds. We did that to the extent of collecting data for 
our research, but otherwise, we trust the poor to spend the funds wisely" (Budsock 2016). While GiveDirectly, in line with the unconditional grant approach, rejected the traditional monitoring activities, the seemingly innocuous reference to "research" indexes something much more profound that goes to the heart of these new efforts to trust.

Trust is not an unfamiliar topic to anthropology (Gambetta 1988; Englund 2002; Sillitoe 2010; Jiménez 2011) or indeed the social sciences and humanities more generally (Fukuyama 1996; Warren 1999; Hardin 2006). But I am particularly interested in the relation between trust and freedom. A number of my interlocutors who either designed or helped to manage the grants brought up the concept of freedom. I was sitting with Joyce Kamau, a civil servant in the Secretariat for the child grant. ${ }^{8}$ We were together in her office on the fourth floor of a rather non-descript building in the government district of Nairobi. As we discussed the initiative and complaints often levelled at it, she seemed to grow impatient, eventually saying to me with exasperation, "But you see, [AUTHOR NAME REMOVED], the program is good, because it gives people freedom and choice. People can use the money for what they want." Joyce's emphasis on freedom and choice echoed the quality of flexibility, mentioned by the NGO worker in the preceding section. These actors believed that by giving money, and trusting them with it, recipients were also being given freedom, choice and flexibility to draw on their own knowledge in the market.

Peter Johnson, in discussing the origins of trust, argues that it concerns "the variety of ways in which agents become conscious of the freedom of others" (Johnson quoted in Seligman 2000, 63). This connects closely to what the philosopher Annette Baier has argued, in a classic piece that has attempted to tease apart the differences between a trusting and a contractarian transaction; that trust is "letting other persons...take care of something the trustor cares about, 
where such 'caring for' involves some exercise of discretionary powers" (Baier 1986, 240). Baier further suggests that the most important things to be entrusted to people are those which only thrive if receiving some form of interference. She offers the example of entrusting a child to one's separated spouse. Her point is that we must care not only very deeply for the thing that is being entrusted, but also carry with us an expectation that the trustee will work on that thing entrusted in ways that will transform it. Similarly, in trusting grant recipients the benefactors expected them to use their discretionary powers to transform the grants into something else by utilizing them in the market without the guidance of experts.

While Joyce Kamau might have given the impression that any use of the money was acceptable, in reality, she and others associated with the grants, had various shifting ideas around what sorts of transformations the money should generate. These sorts of ideas were determined by the benefactors, the trustor, in the existing hierarchical charitable gift relationship. The benefactors trust for the recipients involved expectations about whether the values and strategies of the beneficiaries were proper to their social, political and biological condition. Yet, these expected values and strategies were not always very clear to those in Korogocho. Indeed, the grants generated an anxiety among recipients and local bureaucrats concerning what would either be a responsible use of the money or what sorts of personal transformation should be generated by the money. Later in the article however, I explore one discourse, of hard-work and entrepreneurialism, that was felt strongly by those in Korogocho, and which bureaucrats believed important to the slum's relationship to the charitable economy.

As we have seen, the notion of trusting the poor in the unconditional cash grants is a prominent one. Yet, as we saw with GiveDirectly, research into the poor recipients continues. While this may seem to go against the notion of trust, it actually goes to the heart of any relationship 
whether more contractarian or trust based. Although individual monitoring may cease thus introducing a certain form of freedom for grants recipients in the charitable economy, for the hierarchical relationship between donors and their recipients to continue requires a knowledge of each other. So, even in those relationships in which trust is introduced, like the grants, some verification that this trust was well placed is essential. Indeed, while trust might preclude close monitoring and control, it must include some sort of process or action which would determine if one was justified to trust. Otherwise, of course, trust would equate to blind faith. Therefore, in the new trustful unconditional grants, it is important to recognize their part in a wider, longstanding, precarious charitable economy that is formed within certain, global political and economic relationships; most crucial of these relationships is the one between the donors and the poor. This relationship involves an assumption of a common formal identity and then the subsequent charitable efforts to help achieve a substantive identity. Meaning that efforts to verify the achievement of that substantive identity remain in a manner that circumscribes recipient's freedom, and which have important consequences. In short, the gaze of the donor, which characterizes the development and humanitarian apparatus across the world endures in new efforts to trust the poor. But in certain ways, it also becomes more apparent. As regulation is stripped back, the existing contractarian hierarchical relationship is made ever more vulnerable as attempts are made to transition it into a trusting one. This vulnerability is undoubtedly a part of any attempt to build a relationship characterized by trust; trust, as everybody knows, takes much time to build but far less to break.

\section{The precarious charitable economy and the slum-level bureaucracy}

As I have already mentioned, the grants emerged from within the long-standing social relationships, norms and values of the precarious, charitable economy in Korogocho. Bureaucrats who had lived and worked in Korogocho for a many years understood them as just the latest experiment in a long-line of development and humanitarian ideas that have come into 
the slum, which have included, among many other things, infrastructural and environmental improvements, food aid, economic empowerment, and HIV/AIDS interventions. Later, I explore this economy in more depth as well as the form of claim-making that takes place within it, but here I introduce its bureaucrats.

The charitable economy has established a bureaucracy in Korogocho that does not resemble the more formal bureaucracies, often governmental or quasi-governmental, that have been extensively documented by anthropologists (Herzfeld 1993; Feldman 2008; Gupta 2012; Mathur 2015). It is also dissimilar to what the political scientist Michael Lipsky (1980), described as a street-level bureaucracy, comprising of schools, police, welfare departments and so on, which are responsible for implementing policy. ${ }^{9}$ The bureaucracy in Korogocho, in contrast, was a small army of social workers, community workers and community health workers that formed into an informal, fluid, and fragmented slum-level bureaucracy. These actors do not simply implement policy, but work to attract and manage a precarious, unpredictable and ever-shifting portfolio of development, humanitarian and social welfare interventions in the slum's charitable economy. As these workers go about their work, they are on a permanent state of vigilance for new sources of funds and resources that may be coming into the slum. They jostle to secure short-term pieces of work from individuals, NGOs and government departments, on a range of different issues including water and sanitation, HIV/AIDS, nutrition, and human rights. Some of these bureaucrats have been born or have been educated in Korogocho. Some live within the slum proper, where mud and corrugated iron shacks dominate, while others live in the low-income estates that border it, within houses of slightly better, if still dubious, quality. A few others, such as the manager of a local NGO introduced below, travel from further away to do their work. Whether living outside or within the slum, each day they set about their varied work from measuring babies' weight at the local 
clinic to cajoling groups of youth to attend an entrepreneurship workshop to organizing local women into savings groups. There were also differences within this loose, informal bureaucracy in regard to wealth, status, education levels, as well as authority, and bureaucrats sometimes sought to demonstrate these distinctions to those around them. Yet, what was also clear was the concern bureaucrats had for the people of Korogocho. For instance, a Community Health Worker visiting a house might often provide the inhabitants with money or food from their own pocket. A local NGO worker might go beyond their day job by giving advice, for instance on farming strategies and current crop prices, as well as helping to connect a slum dweller engaging in some farming with a buyer. In this way, while the bureaucrats featured in this article are distinct, they are also part of the world of slum dwellers. In fact, in a place like Korogocho, it is very difficult to say who are insiders or outsiders. Instead, these forms of activity outlined above, as well as the activities presented in this article can be understood, I venture, as a form of mutuality. While there is now a rich literature on this mutuality in subSaharan Africa, rarely are bureaucrats included within them (Bähre 2007; Shipton 2007; Rodima-Taylor 2014; Rodima-Taylor and Bähre 2014). I contend that the charitable economy's long history in Kenya, since the colonial era, has created a certain mutuality that may be studied on its own terms, and which are revealed in the grant programs discussed in this article.

\section{Mistrusting the poor}

As I have suggested, in the conventional charitable economy, which continued to operate during my fieldwork in Korogocho, funds raised by the benefactors are transformed into particular gifts. These are delivered to identified recipients who are subsequently tracked and monitored. Local bureaucrats and recipients alike are therefore brought into these intensive bureaucratic processes. In the grants, however, the hierarchy of knowledge was flattened out, or to some extent reversed, with the poor recipient now given the unmediated gift of cash and 
now considered as an expert. This meant that known bureaucratic and technocratic forms, such as skills training were dismissed, while local bureaucratic intermediaries were stood down, representing a hollowing out of bureaucracy. Yet, in the face of this, the local bureaucrats curiously began to introduce new forms of regulation.

The examples from Korogocho of this reintroduction of regulation that I give below could be too readily dismissed as errors of a technical nature, or simply as some form of miscommunication. Instead I believe the regulatory initiatives pursued by the local bureaucrats have a particular significance. This significance emerges from the charitable economy's deep and sustained history in Korogocho. The intermediaries, those local bureaucrats, with a long engagement in, and understanding of, the charitable economy, felt the heavy presence of one particular aspect, its evidential requirements. For them the gaze of the donor never seemed to be far away. And so, despite the best efforts of the policy-makers, the grants could not escape the long-standing norms, values and social relationships within which they were embedded. Therefore, even though the grants sought to instigate a new trustful regime of giving, they could not escape the existing social context of the charitable economy.

Sarah, a Community Health Worker, was one bureaucrat who has worked for many years in Korogocho. When the grants arrived, she was exasperated. "We don't know what they're using the money for", she said. She continued to argue that, "[The institutions] should work hand in hand with us. They should give us information, so we can advise. We should know who is getting the money, so that we can follow up and monitor as well." Across Korogocho, bureaucrats were expressing similar sentiments. The benefactors behind the grants saw themselves as trusting the poor by allowing them their discretion and allowing them to pursue their own strategies. But while these benefactors sought to trust by reducing the monitoring of 
grant recipients, for bureaucrats in Korogocho this trust posed too big a danger that the recipients may appear to lack the requisite wisdom. In short, an attempt to trust seemed to run the risk of jeopardizing a hierarchical relationship, itself already precarious. It appeared that bureaucrats recognized that for the relationship between donors and the poor to continue required work to make the 'correct' behavior of the poor visible to the donor gaze. I present two examples, which I argue focused on reintroducing regulation in two different ways. The first example sought to make all individuals accountable. The second example sought to make certain individuals representational.

June was the manager at Living Faith, the local NGO involved in the administration of the humanitarian grant. She explained to me one day in her office how she understood the grant programs. She began by acknowledging that the program was not serving everyone who needed it but expressed her confidence that it would over time. She suggested that through a succession of tranches, the program would eventually lift all residents of Korogocho out of poverty. While humanitarians often focus on the "most vulnerable", June recognized that all in Korogocho needed assistance. It was her belief that what was important was not trusting the recipients, but nurturing a charitable relationship that endured, successively encompassing every person in need. Furthermore, a trust that allowed charitable recipients the freedom to behave how they wanted, she thought, would jeopardize this relationship. The solution was a reinstatement of regulation. She explained to me how, in the previous phase of the humanitarian grant program, Living Faith had requested the recipients purchase food with the grant and return evidence, in the form of receipts, to the office. The issuing of receipts was completely alien to the local maduka (shops) and Mama Mboga (the term given to women who sell fruit and vegetables at the side of the road) which most residents frequented. As a result, recipients were required to travel to a supermarket in an adjacent wealthier neighborhood. When I spoke to the 
transnational humanitarian NGO about this, the manager of the program explained that this was a misunderstanding on the part of Living Faith. As soon as the NGO had been made aware of this through the complaints of the residents, those residents were informed not only that receipts were not required but that purchases made with the grant money did not need to be confined to food. Many of my informants repeated similar stories, and some of them even in the second program were still holding on to receipts with the expectation they would be required to present them.

The second example I present focusses on the way in which certain individuals were seen as potentially representational of the larger collective of Korogocho. During my fieldwork I came to know Judith, a community worker. She lived outside the slum but had worked with the people of Korogocho for decades working on various contracts for different donors, from alcohol rehabilitation to malnutrition programs. Judith lived close to Korogocho but was regularly within the slum, working from a small office along the main artery road. This office, a conventional shack made from corrugated iron and with no windows, was a hub in Korogocho's charitable gift economy. Community meetings concerned with the many programs she was involved in were regularly held there or in the adjoining church. Judith was particularly well known in the slum and commanded a lot of respect, as well as envy, for her ability to forge and nourish her connections to external patrons and donors. She had gathered an expert knowledge over years of engagement with charities and the government. As one resident once told me, "All good things, they come through Judith.” When I asked Judith how she could work on so many different interventions, she laughed, telling me that she grabs them at the entrance of the slum before they get the chance to visit the Chief. She claimed to have done the same thing to me when I first arrived in Korogocho, assuming I was an NGO worker or donor. These bureaucrats play an important role in looking to represent the people of 
Korogocho and make claims on the charitable gift economy; something that anthropologists have observed in other parts of the world (Elyachar 2006; Welker 2012, 2012; Whyte et al. 2013; Scherz 2014).

One day Judith was invited to attend a national meeting concerned with Orphans and Vulnerable Children, a strategic priority in Kenya since the onset of HIV/AIDS in the late 1990s. She returned to Korogocho excited and invigorated. Almost immediately she called a meeting of those enrolled in the government's orphan grant program in her own office. At the meeting, I listened as she informed the assembled attendees that a program evaluation would be taking place, and external consultants would be coming to visit Korogocho to see the impact of the grant on people's lives. Recipients were unsurprised; people from the slum and outside of it had often asked them to participate in a survey or other piece of research in connection with other programs. Judith spent the next few weeks trying to arrange the recipients into small savings groups with one another. Privately to me, she lamented that none had saved any of their grant money. Had the recipients started to do so seven years ago, she thought, they would now have enough to begin some form of income generating business. Yet, the evaluation never happened. When I asked the District Children's Officer, who had also attended the meeting, he told me that the meeting had not described any such process. The national meeting had been a broad discussion of the situation of orphans in the country. Yet unlike the mistake made by Living Faith above, it was entirely understandable that Judith would assume an evaluation might take place, because evaluations remain an integral part of any form of policy, even the grants. Judith's belief that she must impart her expert knowledge through a new bureaucratic process is also instructive though. I regularly heard her talk about the need for the poor in Korogocho to be working harder to make their own income. Part of the reason was that she wanted people to become independent from the grant, particularly as she had a strong sense 
that the grant program itself was unreliable and would likely leave at some point. With a long experience in the charitable economy, she knew that assistance never lasted and could not be relied upon. But Judith offered another reason as we spoke, which I argue is illuminative of a particular aspect of bureaucratic work I am highlighting. After complaining about the recipients' neglect of saving strategies she quickly followed up with "If we do well, you see, more people will be taken onto the program." In saying this she made two important shifts. One was from the individual to the collective. The other was from independence to dependency. Or put another way, the current recipients' independence success became a collective asset for dependency on the grant program. In conversations with Judith during my fieldwork, it was clear that she saw herself as an important intermediary in the charitable economy between donors and the poor of Korogocho, working to build on existing relationships and generate new ones.

This sort of attitude, and the sorts of activities Judith set in motion, has a family resemblance with what Maia Green has described in neighboring Tanzania as "anticipatory development", which, she writes, "refers to the ways in which agents seeking a place in development orders, and associated resource steams, adopt postures premised on the possibility of this emplacement" (Green 2012, 322). Her emphasis is on what certain actors do to get access to the development apparatus. However, what I am drawing attention to is what certain actors to do ensure the continuation of the relationship between these sorts of apparatuses and its beneficiaries. In other words, what needs to be done to keep charitable resources flowing into Korogocho. Further, and importantly, this involved not just working on oneself, but the work on certain people to transform them into the sorts of exemplars that would demonstrate to the gaze of the charitable economy how the community was "doing well". In the next section, I 
take a step back by looking at what it means to make claims in this charitable economy, but then return to this idea of "doing well" in the section that follows it.

\section{Making claims in the charitable gift economy}

As mentioned above, surveys and other forms of research were a strikingly familiar feature for residents in Korogocho and were directly connected to the charitable economy. In fact, residents were regularly visited by the African Population and Health Research Center (APHRC), which also held regular medical camps for residents. One friend of mine equated research, even my own when I first started fieldwork, to what he had come to learn as a "baseline survey"; the research conducted by NGOs with which to later determine the extent of the impact of their intervention. This research and activities, such as that initiated by Judith, were seen by residents and bureaucrats alike as making visible both their suffering and successes. To understand this better, its necessary to look more closely at this charitable gift economy.

Since the late colonial period, Kenya has been a testing ground for the development of novel ideas relating to the governance of populations and their health. While early forms of welfare were modelled on those of Britain, by the 1950s it was something called "community development" that became most popular. Rather than direct assistance to specific individuals and households, the colonial government believed that strong communities would be able to support their vulnerable members. Upon independence, Kenya's first president Jomo Kenyatta followed the established mode of community development in emphasizing the harambee movement, an initiative based on the idea that communities would instigate projects and seek matching state funds through the lobbying efforts of their local members of parliament (Mbithi and Rasmusson 1977). But this movement existed alongside a range of philanthropic endeavors. Philanthropy, as we understand the term today, emerged in the $19^{\text {th }}$ century to 
describe the various charitable institutions that arose in England following the Industrial Revolution and in America following the American Revolution (Sulek 2010, 198). Some of these charitable institutions, which gradually became known as NGOs such as Save the Children and the British Red Cross, have operated in Kenya since the colonial period. But it was in the 1980s that these institutions began to proliferate. As is now well known, the structural adjustment period in sub-Saharan Africa, and including Kenya, resulted in large scale cuts to government health and education services, with NGOs rushing in to fill the gaps.

This NGOization in Kenya continued into the 1990s and 2000s (Hearn 1998), and carries on up to the present moment. These organizations, as well as individual benefactors and social entrepreneurs, have flooded into the country moving to the pockets where poverty and hunger across the country abound, including Nairobi. The widespread use of English, and good travel links, housing and restaurants, has made Nairobi attractive to Kenyan and foreign philanthropists alike. Furthermore, with over half the population living in slums, it offers a convenient site of experimentation for new poverty alleviation and humanitarian technologies (for example see Redfield 2012). Korogocho, as one of the major slums of Nairobi, has become increasingly a magnet for these philanthropic individuals and organizations. One community health worker, Caroline told me, "the government has forgotten the slums, and NGOs have built everything; toilets, water, trenches, orphans going to schools - it's all the NGO," adding that "NGOs don't go through the government so they reach people". Many of the largest transnational organizations, including the World Food Programme and Médecins Sans Frontières, had some sort of presence in Korogocho at the time of my fieldwork, and there was a seemingly endless flow of new initiatives teaching residents to do all manner of things. People learnt how to save their money, start a business, feed their children, stave off alcohol or drug addiction, or even how to use self-defense to fight off attackers. Sometimes people received 
more than just knowledge or skills. For instance, attendees of training sessions might occasionally receive a small per diem, a lunch or sometimes a t-shirt emblazoned with a health message. Others might form connections with an organization which would lead to being invited again to another training session, or even access to food, a loan or something else.

Some people had grown weary of these schemes, having wasted time on a series of training sessions, only to receive nothing at the end of them. One youth worker said to me in English one day, when I bumped into him as he was on the way to meet some UN delegates, "Ah, NGOs. You know what that means? Nothing Going On". Others were fed up of being treated as lower class citizens who must simply wait patiently for aid. Yet despite the skepticism felt towards NGOs people in Korogocho also knew that these institutions remained a significant source of assistance. James Ferguson $(2010,168)$ has argued that NGOs in sub-Saharan Africa, with their assistance and their surveillance of people, look very much like the "social" of the social welfare states. However, while Caroline, the community health worker mentioned earlier might agree with this, the situation is somewhat more complex. In Kenya, as in other subSaharan African countries, public health, humanitarian and social interventions have increasingly been delivered through international partnerships, involving nation-states, multilateral institutions such as the World Bank, UN and WHO, and NGOs (Brown 2015). This has made claim-making difficult and confusing. A story recounted to me several times by community workers during my fieldwork is illustrative. A large gathering of residents, who had not been enrolled onto an earlier phase of a humanitarian grant, funded by an NGO but with government involvement, descended one day upon the Chief's Camp. There they chanted haki yetu (our rights). The protest, I was told, came from representatives of the eastern-Cushitic population in Korogocho who have felt historically marginalized by the Kenyan state. They also felt that their members had been overlooked by the charitable gift economy. Drawing on 
an increasingly prevalent discourse of rights and justice in Kenya, they demanded their inclusion in the program as their entitlement on the basis of citizenship. Judith, the community worker whom we met earlier, remembered the event well. She laughed as she recounted the story to me. "It was not about their rights", she told me, "this is charity". Here, Judith rejected their rights-based claim-making aesthetic as fundamentally unsuitable to the charitable gift economy.

Attempts like this to stage protests on the basis of rights and citizenship were not very common in Korogocho. Largely because it was not always particularly clear, even if there was government involvement, that it was an appropriate form of claim-making. Instead, the overwhelming experience of residents was to hope and wait patiently for assistance (see also Auyero 2012). Those residents who had managed to secure some assistance would say, $n i$ bahati tu (it is just luck). Or if their neighbor was getting help one might shrug and say, jirani yangu ako na bahati (my neighbor has luck). Their sense of luck was linked to the reality of what was, to most people in Korogocho, a largely unknowable charitable gift economy. Moreover, the relationship between residents and the economy was precarious. Residents in Korogocho never knew when assistance might arrive, when it might transform into something else, or when it might leave. It was the same for the grants. But this did not make the residents of Korogocho powerless. Instead, they sought to align themselves with bureaucrats, like Judith, who worked not only to make the residents suffering and success visible, as we have already seen, but also was the conduit through which the subsequent resources flowed.

\section{The hard-working poor and their entrepreneurialism}

The effort by Judith to re-regulate the cash grants can be understood better by looking more closely at the expectations embodied in grant programs. That is, the sorts of transformations that the grants are expected to generate. As I have been arguing, while the grants might offer 
the poor the freedom to pursue their own sorts of strategies and values, this freedom is not unbound. Indeed, as the anthropologists of ethics have argued, freedom can only ever be understood in relation to historically constituted social relationships and discourses (Laidlaw 2013). Yet, I am drawing attention to a more specific instance of this, showing how the attempt to build a relationship characterized by trust required the making visible of behaviors. In relation to social and humanitarian grants in Kenya, to understand what behaviors needed to be made visible, we need to look more closely at the idea of work and the informal economy.

One place to start is a prominent publication that has drawn attention to grants in the global South (Hanlon, Barrientos, and Hulme 2010). It is important to note that this publication is not simply an academic commentary on the emergence of grants in Kenya and beyond, but as I found out, also part of performing them. On several occasions, I saw NGO workers reading the book in cafes, and it was also for sale in some of the book shops frequented by both the Kenyan middle-class and expatriates. In the book, the authors extol the virtues of the poor. For instance, they write, "The poor really are different from the better off. If you give money to a person who is relatively well off, such as one of the writers of this book, he or she is likely to take an extra holiday or buy better wine. The poor, on the other hand, find that the cash encourages them to work harder, because they are no longer caught in the poverty trap and can now see a way out" (Hanlon, Barrientos, and Hulme 2010, 173). But the grants in Korogocho combined this idea that they encouraged the poor to work hard and escape from their poverty, with another one concerning how they would facilitate existing forms of care in the household, particularly in regard to nutrition, health and education. In total, the grants are seen as apparently facilitating the poor's existing virtues of working hard, fighting their way out of their own poverty, and caring for the household; the same poor who presumably do not think about leisure. A global constituency of "the poor" and their now positive characteristics is constantly reaffirmed in 
publications like this aimed at a worldwide audience. ${ }^{10}$ This brings echoes of Jacques Rancière's (2003) critique of those philosophers and sociologists who defined the virtues of those at the "bottom". In much philosophy and sociology, he wrote, "One who is a shoemaker by nature should make shoes and nothing else" (Rancière 2003, 27). Drawing material from nineteenth century France, Rancière (2012) showed that workers engaged in many other activities, besides those often assumed of them, including writing poetry, letters and diaries. But when those behind and connected with the grants emphasized how the poor simply strive to escape poverty or care for those household members in poverty, they stay close to the idea of only shoemaking for those at the bottom. Any wider extra-work activities, such as leisure, are assumed to be undesirable for the poor. Yet, in reality of course, recipients in Korogocho regularly used the grants for non-work-related activities in order to make their life in poverty worth living. Many I knew would celebrate on the day they received the grant by buying meat and having a good family meal. Another person I knew described to me how she sometimes used the grants to buy cosmetics for her daughter. These sorts of things would largely remain hidden from the donors, as would other sorts of behavior discussed in the last section of the article. But, as we saw earlier, the particular discourse of hard-work remained an important part of local bureaucrat's own regulatory work.

The emphasis on the hard-working poor also taps into a quite specific vision of work when it moves to places where formal employment is the exception rather than the norm. This is exemplified by Judith's attempt to organize the women into savings groups. There she sought to present them to the gaze of the donor as exemplars of self-reliance and entrepreneurialism, discourses of which are wide-spread and deeply ingrained in Kenya, as they are elsewhere (Elyachar 2002; Lazar 2004; Rajak 2008). The Kenyan government has long promoted these values, establishing schemes such as the Youth Enterprise Development Fund and the Women 
Enterprise Fund. At the same time, the number of banks and NGOs have increasingly, since the 1990s, sought to give microloans to budding entrepreneurs. These schemes have their own history in Kenya, but also join a global social and economic policy which considers that the latent entrepreneur inside every one of the poor might be unleashed only by granting them access to finance (Soto 2000). They also join a much more long standing trend towards entrepreneurialism in public life (Harvey 1989).

John, a married father of two, as well as a friend of mine and a one-time recipient of the humanitarian grant, believed that the entrepreneurial discourse reflected a misunderstanding of his needs and those of others. As he described it, NGOs would come to the slum, observe the multitude of small businesses operating along the roadsides, and conclude that residents were all interested in pursuing entrepreneurship. John believed that most people running small businesses would have preferred other forms of work. Construction work was physically demanding, and worse, very unstable. Factory work in the nearby Industrial Area would be steady and pay well but owners demanded bribes. Some sort of office work, whether for an NGO or the government, was often most desired. During fieldwork, John had bowed to pressure to harness his apparently latent entrepreneurial self, despite little enthusiasm for it, and was working with some of his peers to start their own water stand pipe business. He told me often that he would have preferred help obtaining a steady, reliable job for someone else. Four years after my fieldwork, John eventually did manage to secure a job, working on commission, selling health insurance.

We have already seen how Judith worked to create exemplars for an evaluation that never happened. But I also regularly observed during my fieldwork local bureaucrats directing evaluation consultants and other visitors to the same particular individuals within Korogocho 
who appeared to be running successful businesses. There are two further key points to be made about these exemplars. Firstly, these were exemplars not of the suffering of the poor, but of the success of the poor. Anthropologists have frequently shown how such things as biological vulnerability might form the basis of claims (Petryna 2002; Nguyen 2010), but often less remarked has been how claims might also rely upon the character of the poor. It could be said that philanthropists rely upon communities to give them not just stories of Agamben's (1998) bios, but tales concerning their zoe. The second point to be made is that the bureaucrats saw these exemplars as tools to help build enduring relationships between benefactors and beneficiaries, not just to contribute to a particular image of the abstract category of the poor. David Neves and Andries du Toit have argued in their study of the informal economy in South Africa, that "Economic activity is neither understood, nor is its viability judged, simply in relation to the maximization of profit" (Neves and du Toit 2012, 145). Indeed, as anthropologists know only too well, a range of values beyond the creation of profit characterizes economic life. But we might also consider that certain types of economic activity might be both orientated around profit but also cultivated as a form through which to allow other sorts of resources to flow. In Korogocho, Judith considered a specific form of economic activity to be important, not for profit, but to access the resources of not-for-profits.

\section{Mobility: Allowing but hiding discretion}

While the reinstatement of regulation associated with the control of recipients or the creation of particular exemplars was perhaps most striking, it was not the only local bureaucratic work involved. Also involved was work, as mentioned much earlier in the article, to trust the poor, allowing them but hiding their discretion. This was required because there still lingered regulation around the grants. One prominent discretion concerned residents' strategies of mobility that challenged the spatiality assumptions built into the grants. 
Unconditional grants offer radical new imaginations around work and welfare. Yet, as we have seen, they emerge out of and do not always challenge long-standing social relationships, norms and values around redistribution. In Kenya, the grants were part of a larger charitable regime of redistribution. This has, since the colonial period, taken on an often experimental and patchwork nature, even when the state has been involved. In Nairobi, to the extent that the plight of the urban poor has been recognized, the little assistance that has been made available has travelled to a handful of the larger slums, such as Korogocho. Yet, even though Korogocho's bureaucrats have witnessed and been part of this flow, many of them remain critical. They viewed it as part of a long-standing and perverse situation in which NGOs depended on the maintenance rather than the elimination of poverty in Korogocho. One community health worker, Rose, once told me that NGOs come, take photographs of the poverty and leave. "Wanawatumia watu kama daraja" (lit. they are using people like a bridge), she had said. It was the NGOs, she further explained, that depended on the poor of Korogocho. In turn, the residents of Korogocho devised strategies to tap into any assistance that did reach the slum. Stories abounded among the local bureaucrats of people seeking to convince them that they resided in Korogocho and that they were suitably impoverished; one story had a woman attempting to convince a bureaucrat that a toilet was actually her house. The poor, it appeared to the poor and their bureaucrats, were required not only to be impoverished but rooted in what many of them believed to be if not the source but a major factor in the continuation of poverty.

The grants in Korogocho had, for a long time, relied upon these existing spatialities. To receive a grant, one should be a local resident. But bureaucrats challenged these assumptions of spatiality. Judith understood these assumptions and recognized that donors would only continue to support and trust recipients if they remained in Korogocho. Yet she also knew that some recipients left Korogocho and returned every few months only to pick up their payments. 
Others arranged for somebody else to pick them up for them. One day I had stopped by Judith's office, an inconspicuous wooden hut in a prime position on the main road. I often popped in to say hello to Judith and rarely left without the latest gossip. That day we talked about the child grant recipients, some of whom, she told me, had begun the process of properly establishing themselves in their rural homes. Her eyes lit up as she described, excitedly, how some of these recipients would pay her a visit in her office with photographs of the houses they had built in their rural homes. She also confided in me that she encouraged their plans and did not reveal them to her superiors. While the grant donors expected the money to go to the children in the household, for Judith, it made sense for the people raising them to establish a permanent presence in the areas many believed to be their proper and legitimate home. This would offer them a place of security; a need they were acutely aware of as a result of the hundreds of thousands of fellow citizens forced from their homes after the violence following the disputed presidential elections in 2007 and 2008.

Judith's sentiments became particularly clear one day when I accompanied her on a surveying procedure to identify recipients for the humanitarian grant. She became embroiled in an argument with a young man who she outrightly refused to include in her survey. She told him that if he really lacked the financial means to live in Nairobi he must return to his rural home. The man laughed, telling her that Korogocho was his home now. Turning to me, Judith said, “Are people IDPs [Internally Displaced Persons]", she said, tapping into an English acronym popularized after post-election violence in 2007 and 2008, "or are they migrants? Are they forced to come here? People here, they shouldn't live here, they should go back to their homes." Judith tapped into a discourse with longer historical continuities. During the late colonial period, the Voluntarily Unemployed Persons Ordinance, while ultimately impossible to implement, gave power to the police to arrest the unemployed and return them to the native 
reserves or to find jobs for them. Upon independence, President Jomo Kenyatta urged Kenyans to rudi mashambani (return to the farms) as a means to build the nation. Today, bureaucrats, like Judith, similarly urge residents to return to their rural homes, less to make the national collective and more to maintain the household one. Yet, assumptions of mobility and spatiality were built firmly into the grants.

It was not only local bureaucrats in Korogocho but also higher-level civil servants that shared Judith's sentiments. They had begun challenging the way in which the child grants in particularly rooted the poor in Nairobi by only allowing them to be physically collected at one place where the recipient was registered. Eventually, the challenge by the Kenyan bureaucrats was won, and a policy change was implemented that would allow grant payments to be withdrawn from any part of the country. James, a bureaucrat in the Secretariat for the child grant, told me that now, "You can get the cash and then you can move out of Nairobi back to your rural area. The cost of living in Nairobi now is too high and money doesn't go that far, and Nairobi, it's too congested these days." The challenge had been a hard one to mount because at the time debates were raging around placing conditions on the grants. For those in favor of unconditional grants, a broad donor gaze was sufficient, yet existing audit cultures asserted themselves, creating a tension that continues today. High level Kenyan bureaucrats faced these global audit cultures that remained within the charitable regime and challenged them to allow strategies of mobility. While these challenges raged on, local bureaucrats like Judith continued to work to hide mobility from the donor gaze and any lingering audit policies that sought to root the poor.

\section{Conclusion}

At the dawn of the $21^{\text {st }}$ century, Kenya became a hub for new challenges to bureaucratic hierarchies through the idea of cash grants. Experiments in unconditional cash grants have 
taken place throughout the country, in which the poor have been trusted with money with nostrings-attached. These grants advertise themselves as both trusting the poor and suspicious of regulation and expert knowledge. They therefore join a broader movement that has been labelled as post-bureaucracy (Heckscher and Donnellon 1994), while remaining connected to a long history of social and humanitarian assistance that has similarly sought to disrupt the form and textures of hierarchy, from recent calls for a Universal Basic Income to earlier ideas proposed by Thomas Paine in his Agrarian Justice in the late $18^{\text {th }}$ century. It is therefore no surprise that the grants are favored by those across the political spectrum who are wary of centralized authority. A utopian world free of red-tape is sometimes imagined, in which people's creative capacity and their ability to flourish is only held back by the twin evils of paternalism and poverty.

Local bureaucrats in Korogocho have for many years been part of the development and humanitarian apparatus. They have carried out a broad range of work involving finding recipients, channeling resources, such as food or medicine, to them, educating them and monitoring them. But the new effort by donors to trust the poor with grants posed not only a problem to bureaucrats' own livelihood, but also what they believed to be an existential risk to relationships within the charitable economy. The motivation behind this article was to address the puzzle of why bureaucrats responded to these attempts by seeking to reintroduce paternalistic regulation. I have argued that they doubled down on what they had already been doing, working as intermediaries to translate between the two broad categories, donors and beneficiaries, the expectations and values of each.

I have resisted the more conventional interpretations that the re-introduction of regulation was either the mechanical response of bureaucracy, or that the bureaucrats themselves were 
concerned simply with self-preservation or making a distinguishing themselves from those they served. I have also diverged from the interpretation that sees bureaucracy and its related practices as a way in which subjects might be made. Instead, I have argued that the bureaucratic response can be understood as a form of care, particularly in regard to a relationship (see also AUTHOR NAME REMOVED 2017). This involved attempts to transform and show the expected transformation of the gift recipients, while at the same time hiding behaviors and values that might seem antithetical to those expected by the donors.

Across the globe, hierarchies and bureaucracy are being challenged. The internet, blockchain technologies, peer-to-peer exchanges, and so forth, seem to promise a utopian world in which exchanges, both economic and social, can take place between equals without intermediaries. Of course, these attempts seek to take the baton from the market, itself a mechanism long seen to dissolve existing hierarchies. The grants explored in this article embrace this market, and combine it with hierarchies of redistribution, but in the process seek to flatten, invert and hollow out these very hierarchies. In doing so and seeking to trust the poor with cash, those behind the grants at times seem to ignore the wider hierarchical social relationships in which they are enmeshed leaving instead a residual and somewhat romantic view that trusting the poor is a simple act that can be detached from a highly unequal relationship.

This article has shown how efforts, embodied by the grants, to rework hierarchies leave unchanged, inhabit and are affected by long-standing, global and national political and economic relationships, norms and values in Kenya and beyond. The specific efforts to trust the poor ignored the way in which not only can relationships in the charitable economy rarely be trusted by the poor to provide on-going assistance, but that building any relationship based on trust necessitates the making visible of parties' behavior. This is what local bureaucrats 
sought to do, and in doing so they revealed themselves to be persons with their own distinct ethical projects.

The bureaucratic response I have examined in this article, I argue, forces us to question unthinking assumptions that it is right to simply trust the poor or that bureaucrats are unnecessary or even troublesome intermediaries. But it also offers us an opportunity to further reflect on wider efforts and often utopian imaginations of a world free of hierarchy and bureaucracy.

\section{$\underline{\text { Acknowledgements }}$}

I would like to express my sincere thanks to the editor and the anonymous reviewers for their profoundly generous engagement in this article from the outset. Its faults, which remain my own, are unimaginably fewer had I not received such helpful and extensive feedback. I would also like to express my thanks, Harri Englund, Sian Lazar and Mais Green, who saw this article when it was a $\mathrm{PhD}$ thesis chapter.

\section{Bibliography}

Agamben, Giorgio. 1998. Homo Sacer: Sovereign Power and Bare Life. Stanford, California: Stanford University Press.

Ansell, Aaron. 2014. Zero Hunger: Political Culture and Antipoverty Policy in Northeast Brazil. Chapel Hill: University North Carolina Press.

Auyero, Javier. 2012. Patients of the State: The Politics of Waiting in Argentina. Durham NC: Duke University Press.

Bähre, Erik. 2007. "Reluctant Solidarity Death, Urban Poverty and Neighbourly Assistance in South Africa." Ethnography 8 (1): 33-59.

Baier, Annette. 1986. “Trust and Antitrust.” Ethics 96 (2): 231-60. 
Bornstein, Erica. 2009. “The Impulse of Philanthropy.” Cultural Anthropology 24 (4): 622651.

Brown, Hannah. 2015. “Global Health Partnerships, Governance, and Sovereign Responsibility in Western Kenya: Partnerships and Sovereign Responsibility.” American Ethnologist 42 (2): 340-55.

Brown, Hannah, and Maia Green. 2017. "Demonstrating development: meetings as management in Kenya's health sector." Journal of the Royal Anthropological Institute 23 (S1): 45-62.

Budsock, Andrew. 2016. "Unconditional Cash to the Poor: An Interview with GiveDirectly." Impakter. October 25.

Das, Veena. 2015. Affliction. New York: Fordham University Press.

Du Gay, Paul. 2000. In Praise of Bureaucracy: Weber - Organization - Ethics. London; Thousand Oaks, California: Sage Publications Ltd.

Elyachar, Julia. 2002. “Empowerment Money: The World Bank, Non-Governmental Organizations, and the Value of Culture in Egypt." Public Culture 14 (3): 493-513.

- 2005. Markets of Dispossession: NGOs, Economic Development, and the State in Cairo. Durham NC: Duke University Press.

—. 2006. "Best Practices: Research, Finance, and NGOs in Cairo.” American Ethnologist 33 (3): 413-26.

Englund, Harri. 2002. From War to Peace on the Mozambique-Malawi Borderland. Edinburgh: Edinburgh University Press.

Feldman, Ilana. 2008. Governing Gaza: Bureaucracy, Authority, and the Work of Rule, 1917-1967. Durham, NC: Duke University Press.

Ferguson, James. 2010. “The Uses of Neoliberalism.” Antipode 41: 166-184. 
—. 2013. "Declarations of Dependence: Labour, Personhood, and Welfare in Southern Africa." Journal of the Royal Anthropological Institute 19 (2): 223-242.

—2015. Give a Man a Fish: Reflections on the New Politics of Distribution. Durham

NC: Duke University Press.

Foucault, Michel. 1979. The History of Sexuality v. 1. Translated by Robert Hurley. London: Penguin.

—. 1990. “Social Security.” In Politics, Philosophy, Culture: Interviews and Other Writings, 1977-1984, edited by Lawrence Kritzman, 160-77. New York, NY:

Routledge.

_ 1991. Discipline and Punish: The Birth of the Prison. Translated by Alan Sheridan. Penguin.

—. 2008. The Birth of Biopolitics: Lectures at the College de France, 1978-1979.

Translated by Graham Burchell. Palgrave Macmillan.

Fukuyama, Francis. 1996. Trust: The Social Virtues and The Creation of Prosperity. Free Press.

Gambetta, Diego. 1988. Trust: Making and Breaking Cooperative Relations. Oxford; Massachusetts: Blackwell Publishers.

Goodell, Grace E. 1985. "Paternalism, Patronage, and Potlatch: The Dynamics of Giving and Being Given To [and Comments and Reply].” Current Anthropology 26 (2): 247-66. Green, Maia. 2012. "Anticipatory Development: Mobilizing Civil Society in Tanzania." Critique of Anthropology 32 (3): 309-33.

Guérin, Isabelle. 2014. "Juggling with Debt, Social Ties, and Values: The Everyday Use of Microcredit in Rural South India." Current Anthropology 55 (S9): S40-50.

Gupta, Akhil. 2012. Red Tape: Bureaucracy, Structural Violence, and Poverty in India. Durham NC: Duke University Press. 
Hanlon, Joseph, Armando Barrientos, and David Hulme. 2010. Just Give Money to the Poor: The Development Revolution from the Global South. Sterling, VA: Kumarian Press.

Hardin, Russell. 2006. Trust. Cambridge: Polity Press.

Harvey, David. 1989. "From Managerialism to Entrepreneurialism: The Transformation in Urban Governance in Late Capitalism.” Geografiska Annaler. Series B, Human Geography 71 (1): 3-17.

Haynes, Naomi. 2012. "Pentecostalism and the Morality of Money: Prosperity, Inequality, and Religious Sociality on the Zambian Copperbelt." Journal of the Royal Anthropological Institute 18 (1): 123-139.

Haynes, Naomi, and Jason Hickel. 2016. "Hierarchy, Value, and the Value of Hierarchy." Social Analysis 60 (4): 1-20.

Hearn, Julie. 1998. “The 'NGO-Isation' of Kenyan Society: USAID \& the Restructuring of Health Care." Review of African Political Economy 25 (75): 89-100.

Heckscher, Charles C., and Anne Donnellon. 1994. The Post-Bureaucratic Organization: New Perspectives on Organizational Change. Thousand Oaks, California: Sage Publications.

Herzfeld, Michael. 1993. The Social Production of Indifference. Chicago ; London: University of Chicago Press.

Hobart, Mark. 1993. An Anthropological Critique of Development: The Growth of Ignorance. London; New York: Routledge.

Jiménez, Alberto Corsín. 2011. "Trust in Anthropology.” Anthropological Theory 11 (2): 177-96.

Laidlaw, James. 2013. The Subject of Virtue. Kindle Edition. Cambridge: Cambridge University Press. 
Lazar, Sian. 2004. "Education for Credit Development as Citizenship Project in Bolivia." Critique of Anthropology 24 (3): 301-19.

Lewis, Joanna. 2000. Empire State-Building: War \& Welfare in Kenya, 1925-52. Ohio: Ohio State University Press.

Lipsky, Michael. 1980. Street-Level Bureaucracy: Dilemmas of the Individual in Public Services. New York: Russell Sage Foundation.

Mathur, Nayanika. 2015. Paper Tiger: Law, Bureaucracy and the Developmental State in Himalayan India. Cambridge: Cambridge University Press.

Mbithi, Philip M., and Rasmus Rasmusson. 1977. Self Reliance in Kenya: The Case of Harambee. Uppsala, Sweden: Nordic Africa Institute.

Miller, Peter, and Nikolas Rose. 1990. “Governing Economic Life.” Economy and Society 19 (1): $1-31$.

Moodie, Megan. 2008. “Enter Microcredit: A New Culture of Women’s Empowerment in Rajasthan?" American Ethnologist 35 (3): 454-465.

Mosse, David. 2005. Cultivating Development an Ethnography of Aid Policy and Practice. London; Ann Arbor, MI: Pluto Press.

Neves, David, and Andries du Toit. 2012. "Money and Sociality in South Africa's Informal Economy.” Africa 82 (Special Issue 01): 131-149.

Nguyen, Vinh-Kim. 2010. The Republic of Therapy: Triage and Sovereignty in West Africa's Time of AIDS. Durham NC: Duke University Press.

Olivier de Sardan, Jean-Pierre, and Emmanuelle Piccoli, eds. 2018. Cash Transfers in Context: An Anthropological Perspective. 1 edition. New York: Berghahn Books. Petryna, Adriana. 2002. Life Exposed: Biological Citizens after Chernobyl. Princeton, NJ: Princeton University Press. 
Rajak, Dinah. 2008. “'Uplift and Empower': The Market, Morality and Corporate Responsibility on South Africa's Platinum Belt." In Hidden Hands in the Market: Ethnographies of Fair Trade, Ethical Consumption and Corporate Social Responsibility, edited by Geert de Neve. Emerald Group Publishing.

Rancière, Jacques. 2003. The Philosopher and His Poor. Edited by Andrew Parker.

Translated by John Drury, Corrine Oster, and Andrew Parker. Durham NC: Duke University Press.

- 2012. Proletarian Nights: The Workers' Dream in Nineteenth-Century France.

London; New York: Verso.

Redfield, Peter. 2012. "Bioexpectations: Life Technologies as Humanitarian Goods.” Public Culture 24 (1 66): 157-84.

Rodima-Taylor, Daivi. 2014. "Passageways of Cooperation: Mutuality in Post-Socialist Tanzania." Africa 84 (04): 553-575.

Rodima-Taylor, Daivi, and Erik Bähre. 2014. "Introduction: Mutual Help in an Era of Uncertainty." Africa 84 (04): 507-509.

Scherz, China. 2014. Having People, Having Heart: Charity, Sustainable Development, and Problems of Dependence in Central Uganda. Chicago: University of Chicago Press. Sealander, Judith. 2003. "Curing Evils at Their Source: The Arrival of Scientific Giving.” In Charity, Philanthropy, and Civility in American History, edited by Lawrence J.

Friedman and Mark D. McGarvie, 217-40. Cambridge: Cambridge University Press. Seligman, Adam B. 2000. The Problem of Trust. Princeton, N.J: Princeton University Press. Shipton, Parker. 2007. The Nature of Entrustment: Intimacy, Exchange, and the Sacred in Africa. New Haven: Yale University Press.

Sillitoe, Paul. 2010. "Trust in Development: Some Implications of Knowing in Indigenous Knowledge.” Journal of the Royal Anthropological Institute 16 (1): 12-30. 
Soto, Hernando De. 2000. The Mystery of Capital: Why Capitalism Triumphs in the West and Fails Everywhere Else. New York: Basic Books.

Stirrat, R. L., and Heiko Henkel. 1997. “The Development Gift: The Problem of Reciprocity in the NGO World." The Annals of the American Academy of Political and Social Science 554: 66-80.

Strathern, Marilyn. 2000. "Introduction.” In Audit Cultures: Anthropological Studies in Accountability, Ethics and the Academy, 1-18. London; New York: Routledge.

Sulek, Marty. 2010. “On the Modern Meaning of Philanthropy.” Nonprofit and Voluntary Sector Quarterly 39 (2): 193-212.

Warren, Mark E. 1999. Democracy and Trust. Cambridge: Cambridge University Press. Welker, Marina. 2012. “The Green Revolution's Ghost: Unruly Subjects of Participatory Development in Rural Indonesia.” American Ethnologist 39 (2): 389-406.

Whyte, Susan R., Michael A. Whyte, Lotte Meinert, and Jenipher Twebaze. 2013. “Therapeutic Clientship.” In When People Come First: Critical Studies in Global Health, edited by João Biehl and Adriana Petryna. Princeton, NJ: Princeton University Press.

Wilson, Richard Ashby, and Richard D. Brown, eds. 2008. Humanitarianism and Suffering: The Mobilization of Empathy. Cambridge: Cambridge University Press.

Zelizer, Viviana A. 1994. The Social Meaning of Money. New York: Basic Books.

\footnotetext{
${ }^{1}$ Living Faith was the development NGO arm of the Living Faith Church, both pseudonyms. The church itself was founded in the 1970s and is now one of the largest churches in Kenya.

${ }^{2}$ It is notable that much discussion around the design of cash grants is orientated around what is termed "graduation", in which it is argued that recipients should transferred to other forms of programs, such as microcredit, in order to prevent their dependency on the grant.
} 
${ }^{3}$ CaLP were at the forefront of advocating for and researching the increasing role of cash transfers in the humanitarian aid industry, as well as coordinating the programs during the large-scale drought affecting the Horn of Africa at the time.

${ }^{4}$ While unconditional grants involved an attempt to limit expert knowledge practices, the categorization work in delimiting the "extreme poor" or "most vulnerable" from a wider population made bureaucracy at the beginning of the program far from redundant. Particular households were selected, and grants directed towards their primary, predominately female, "caregiver." This is in contrast to most existing forms of assistance that aim to work within or through some form of larger collective beyond the household, for example, through group lending (Lazar 2004) or a "community", the latter of which has a long colonial and post-colonial history in Kenya (Lewis 2000).

${ }^{5}$ This is not to say that checking was alien to my interlocutors who were subjected to various forms of proxymeans testing in order to be enrolled onto the program.

${ }^{6}$ But the minimalistic nature of bureaucracy should not be understood necessarily as "government from a distance" (Miller and Rose 1990), in which people were required to check themselves by reaching particular targets (Strathern 2000). Instead, as James Ferguson has recently written in regards to his study of grants in Southern Africa, they involve "a recognition that 'the poor' may be trusted to look after their own best interests" (Ferguson 2015, 194).

${ }^{7}$ Not because money is somehow separate from social relationships (Zelizer 1994)

${ }^{8}$ Pseudonyms are used throughout for all individuals, unless otherwise stated, and for the local NGO Living Faith.

${ }^{9}$ Which itself relies upon a problematic assumption that practice follows policy (Mosse 2005). 
${ }^{10}$ Taken together, the idea of "the poor" as being morally superior and therefore worthy of trust differs to other forms of philanthropy. For instance, Erica Bornstein has documented how some argue that the Hindu dān does not need to involve monitoring if the "donee is carefully selected" (Bornstein 2009, 625). 